Article

\title{
Laser Annealing for Gas-Dynamical Spraying of HA Coating upon a Titanium Surface
}

\author{
Victor Saphronov ${ }^{1}$ and Igor Shishkovsky ${ }^{1,2, *}$ \\ 1 Laboratory of Innovative Additive Technologies, Moscow State University of Technology \\ "STANKIN", 127055 Moscow, Russia; E-Mail: v.saphronov@stankin.ru \\ 2 Lebedev Physical Institute of Russian Academy of Sciences, Samara Branch, \\ Novo-Sadovaja st. 221, 443011 Samara, Russia \\ * Author to whom correspondence should be addressed; E-Mail: shiv@fian.smr.ru; \\ Tel.: +7-846-334-4220; Fax: +7-846-335-5600.
}

Academic Editor: Helmut Cölfen

Received: 29 July 2015 / Accepted: 28 September 2015 / Published: 8 October 2015

\begin{abstract}
Laser post-heating computer controlled detonation spraying (CCDS) and cold spray (CS) hybrid processes were proposed for fabrication of near sub micron structure coatings of hydroxyapatite (HA) + Ti system. Optical and SEM with energy dispersive X-ray analysis and comparative XRD phase analysis were used to evaluate microstructure. After those hybrid processes, no substantial variation in HA composition was noted by structural and phase examination. Nano-sized HA powders can be recommended for laser annealing $\mathrm{CS}$ (LaCS) process. Regimes of laser treatment optimal for increasing the adhesion between the HA and titanium coatings, providing more strength, ductility and decreasing of HA destruction in the coatings were determined.
\end{abstract}

Keywords: computer controlled detonation spraying (CCDS); cold spray (CS); laser annealing CCDS and CS; hydroxyapatite (HA)

\section{Introduction}

Titanium based alloys are widely used for biomedical applications, due to their biocompatibility, high durability, low density and good corrosion resistance. However, titanium is a bioinert material [1], i.e., interface between titanium and bone tissue is a simple interlocking bonding, which can lead to loosening 
of the implant and eventual failure of its implantation. Nevertheless, surface properties (composition, hydrophilicity, roughness and durability) should play a crucial role in implant - tissue osteointegration.

Hydroxyapatite $(\mathrm{HA})-\mathrm{Ca}_{10}\left(\mathrm{PO}_{4}\right)_{6}(\mathrm{OH})_{2}$ ceramics is routinely used in orthopedy to coat implants for improving biocompatibility and bone fixation, as chemical composition and structure of $\mathrm{HA}$ are close to mineral phase of bone. Implant surfaces with HA content offer smaller hydrophobicity and greater wettability. Thus, function of the HA coating on the titanium substrate consists in avoiding fibrous tissue encapsulation on the titanium - bone interface and enhancing titanium osteoconductivity [2,3]. In a great number of studies HA is used as filler in biopolymer compositions for medical applications [4-8]. But strength of such constructions is modest.

Physical vapor deposition (PVD), which includes electron beam evaporation, pulsed laser deposition, cathodic arc deposition, molecular beam epitaxy, ion beam assisted deposition and magnetron sputtering, are the most studied methods of HA coating deposition upon titanium based alloys [3,9-15]. In these methods, HA powder is heated up to extremely high temperatures and delivered to the substrate surface at a high speed. However, reproducibility in results of coating by PVD and plasma spraying is not satisfactory [14]. The reason is lack of comprehensive control of the phase composition, morphology and porosity of the coatings. This explains instability in mechanical and biological performance of the coatings [10,13]. Resulting coatings contain metastable and decomposed phases, which have no biocompatible properties and decay after implantation, thus decreasing adhesion to the surrounding bone as well as to the metal substrate. In our earlier studies, HA layers on Ti were formed by direct laser sintering of $\mathrm{HA}+\mathrm{Ti}$ powder mixture [1,16,17], which showed better bioactivity and biocompatibility. However, HA additive decreases sinterability of the powder mixture. Moreover, since the implant interacts with a living tissue only on the surface, in our opinion, there is no need to spend it for the entire implant volume.

Methods of cold spraying (CS) and computer controlled detonation spraying (CCDS) are comparatively new methods of spraying the powder coatings [18-20]. The basic difference between CS and CCDS is that CS allows spraying powder at high velocities and always in solid state, while CCDS provides lower but comparable velocities and much higher temperatures resulting in spraying powders in liquid state [18]. As a result of comparison for the CS and CCDS composites, one may note that the detonation coatings are heat-hardened owing to the solidification of the sprayed particles. The overwhelming majority of investigations performed in this field are devoted to use of micron-sized particles of one material (usually a metal or a metal based alloy), i.e., to spraying of single component coatings. It was mentioned in some publications that in substantial cases spraying ceramic powders by the CS method is difficult because of absence of plasticity at ceramic particles. However, spraying mixtures of metallic and ceramic particles can already be implemented [19], including the HA + Ti systems [20].

An open question about multimaterial fabrication of protective and biocompatible HA + Ti coatings is adhesion between the HA ceramic and the Ti layers, which initiates future research in this direction. Laser annealing after CS (LaCS) is a new manufacturing process, which combines advantages of supersonic CS and laser heating of the fabricated coatings [21-25]. Ability to deposit materials of different nature (metals, intermetallides, ceramics, etc.), high deposition rates and reduced operation cost, improved coating adhesion are characteristics of this hybrid process. Effects of initial nano-sized HA powder can give additional advantages like strong interfacial coating strength, higher biocompatibility and potentially long lifetime cycle [22]. 
The objective of the present study was to perform a comparison between cold spraying (CS) and computer controlled detonation spraying (CCDS) of sub-micron and nano-sized HA ceramics on the Ti based alloy for medical applications, and to realize an additional laser treatment of the fabricated coating for decreasing its porosity, improving its adhesion and durability. The received microstructures of the coating were evaluated by X-ray analysis, optical metallography, and SEM equipped with EDX analysis.

\section{Experimental Section}

The titanium of the TiGd2 grade $(\mathrm{Ti}>98.1 \mathrm{wt} \%,-36+14 \mu \mathrm{m})$ was supplied from TLS Technik GmbH \& Co., Lennestadt, Germany, (Spezialpulver KG, Bitterfeld-Wolfen, Germany). The HA grade 99.5 wt \% $\mathrm{Ca}_{10}\left(\mathrm{PO}_{4}\right)_{6}(\mathrm{OH})_{2}$ from Medicoat AG (Mägenwil, Switzerland) was preliminarily sieved for near submicron separation $(\sim 5-10 \mu \mathrm{m})$. Nano-sized HA, $\sim 60 \mathrm{~nm}$, was supplied from EV NANO Technology Co. Ltd. (Hefei, China) and used as received. The appearance of the HA powders is shown in Figure 1. Granulomorphological analysis of the micron-sized powders was carried out by optical granulomorphometer ALPAGA 500 NANO, which is an optical sieving system equipped with Callisto image analysis software (OCCHIO, Angleur, Belgium). The substrates were Ti-based medical dental instruments, sandblasted before spraying.

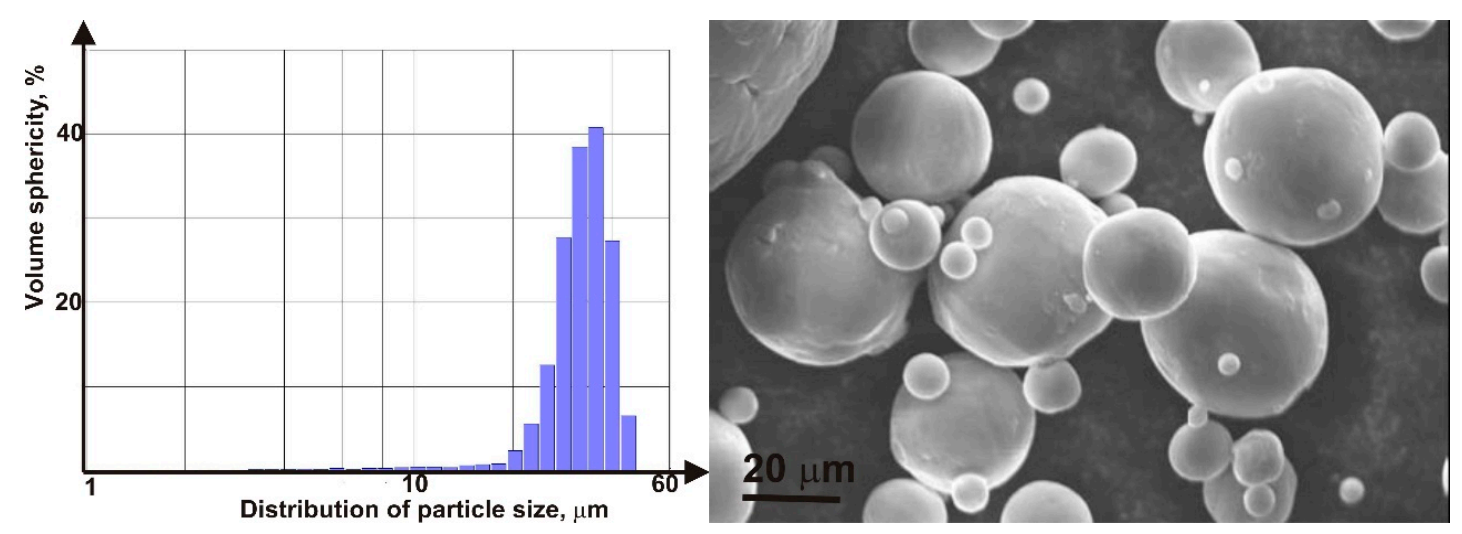

(a)

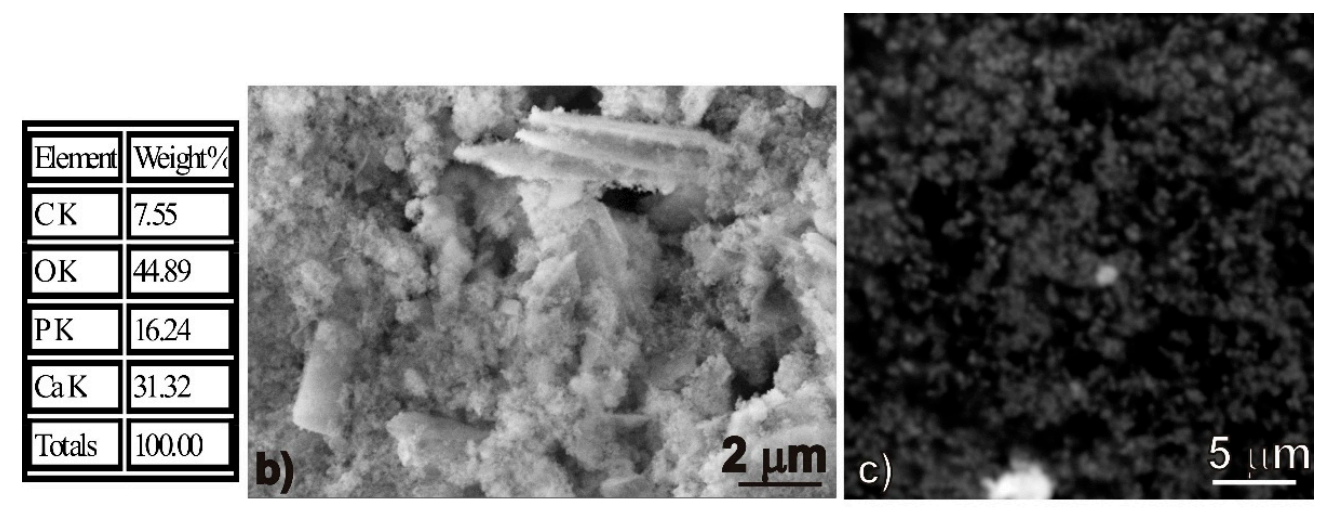

Figure 1. SEM images of initial TiGd2 and HA powders under larger magnification: (a) TiGd2 image and its granulometric distribution; (b) HA of sub micron size from Medicoat Co. (Mägenwil, Switzerland) with EDX analysis; and (c) HA of nano size from EvNanoTech.com Ltd. (Hefei, China). 
Experiments on the CCDS were carried out on the CCDS 2000 installation (DIPI, ENISE, Saint-Étienne, France). Basic parameters of the installation used for the coating deposition and some preliminary results were presented in our last paper [20]. The CS setup at the LIAT (Stankin, Russia) based on the Impact Spray System 5/8 (Haun, Bavaria, Germany) worked under 25 atm. and temperature of $500{ }^{\circ} \mathrm{C}$. The micron-sized HA was used for the CCDS process and the nano-sized HA-for the CS process. For we used nano-sized HA powders, they were preliminarily mixed with titanium in 1:1 ratio by wt. for unproblematic delivering of the powder to the substrate.

After the CS and the CCDS part of samples became a subject of the laser treatment. Our experimental setup for the laser treatment of coated layers included: (a) a continuous-wave Ytterbium fiber LK-200 V IPG (Fryazino, Russia) with wavelength of $1.075 \mu \mathrm{m}$; (b) deflectors for the laser beam scanning in the $\mathrm{X}-\mathrm{Y}$ plane; (c) lens with focused spot of $d \sim 100 \mu \mathrm{m}$ diameter; (d) mechanism for deposition and levelling the powder mixture; and (e) vertically moving cylindrical platform. The laser beam scanned by the meander an area of $50 \times 50$ or $100 \times 100 \mathrm{~mm}^{2}$ and was controlled by the computer through the mechanical deflectors. The treatment was performed in the air. Hatch distance was equal to the laser beam diameter. Under the present study, laser power varied in the range of 10-90 W, scan velocities $v$ were $5-20 \mathrm{~mm} / \mathrm{s}$.

After the laser assisted CS and CCDS the specimens were cut, mounted in the cold-polymerizing mass (CPM), then specimens were first grounded with sand paper of different granulation and finally were polished with special pastes. Macrostructure was evaluated by optical microscopes (Carl Zeiss AxioScope microscope with Axiovision 4.7 image analysis software and Olympus BX51M, Tokyo, Japan). Morphology of the Ti + HA coatings was characterized with a LEO 1450 (Carl Zeiss Company, Oberkochen, Germany) scanning electron microscope (SEM) equipped with an energy-dispersive X-ray (EDX) analyzer (INCA Energy 300, Oxford Instruments, Abingdon, UK) and VEGA 3 LMH (Prague, Czech Republic) with an EDS analyzer (INCA ENERGY GSR P80, Oxford Instruments, Abingdon, UK).

The crystal structures of the coatings were examined by X-ray diffraction on a DRON-3M powder diffractometer (Co $K_{\alpha}$ radiation). Their phase composition was determined using JCPDS PDF data (PCPDFWIN ver. 2.02, release 1999) and the Crystallographica SearchMatch ver. 3.102 program.

\section{Results and Discussion}

\subsection{Microstructural Evaluation}

The CCDS process allows fabricating an HA coating on titanium, which is characterized by pores and voids presence between the Ti and the HA layers (Figure 2a). Thus, in present study, we proposed in the wake of the LaCS process to realize a LaCCDS process.

The Figure 3 shows some results of the laser treatment after the CCDS process in the range of laser powers from 10 up to $90 \mathrm{~W}$ and laser scan velocities of 10-20 mm/s. Under a high laser energy input of more than $40 \mathrm{~W}$ the coated surface had a fully remelted structure with a size of the heat affected zone up to substrate. Under a modest laser power of 20-40 W (Figure 3b,c) the surface structure was characterized by a developed crack net and only below $10 \mathrm{~W}$ this net is absent. However, under high magnification (Figure 4) some cracks remained. Also we observed a laser passage presence (a dot line in Figure 4) on the heated surface. The EDX analysis from the S1-S3 areas is similar to the element 
distribution after pure CCDS process (Figure $2 \mathrm{~b}$ ), which is a positive factor. Ti, Ca, P, O and C element maps are shown in Figure 2b. Undesirable HA decomposition leads to a loss of pharmacological properties of the HA coating which will be discussed later in the sub-Section 3.2. As an intermediate conclusion, we can recommend the laser treatment process to follow the transfer at the regime of laser annealing with a low laser energy input, slow scan velocities and a defocused laser beam.

\section{OM - microsection}

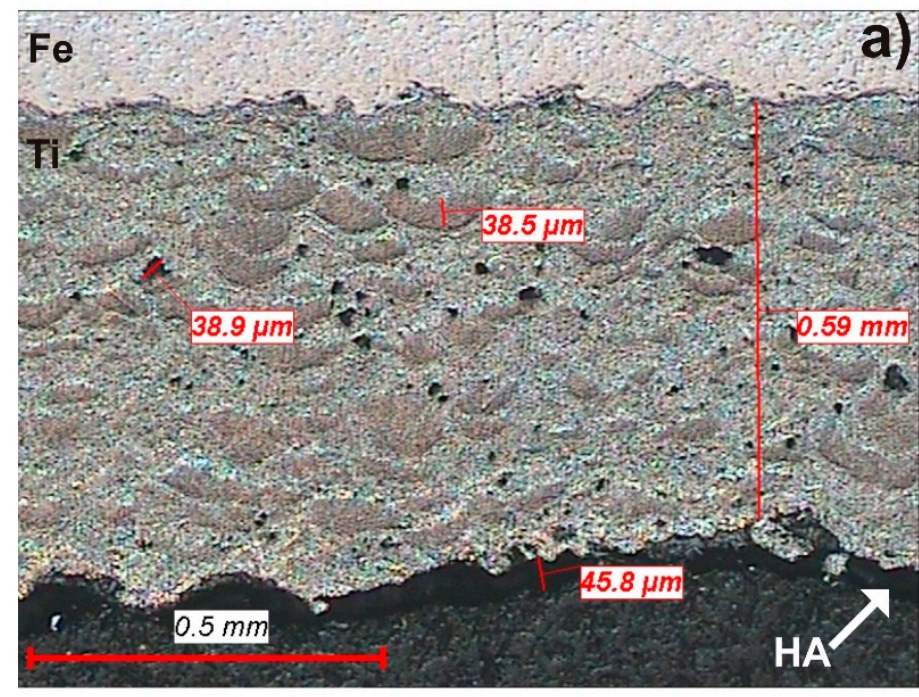

\section{SEM \& EDX analysis}

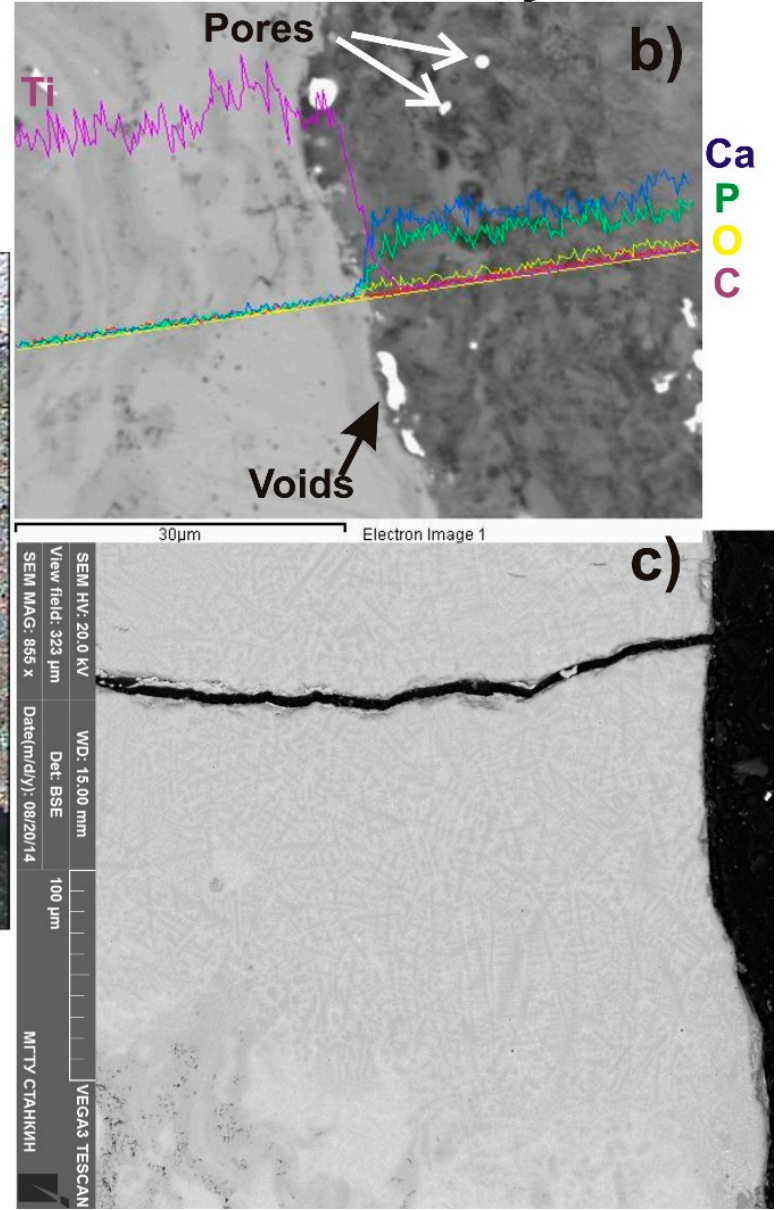

Figure 2. OM image (a) and SEM image (b) with element distribution after CCDS in $\mathrm{HA}+\mathrm{Ti}$ system (Ti, Ca, P, O and C element map is shown on picture). SEM image (c) is a laser treatment of the CCDS surface, see (a).

In Figure 5a-c, the results of the LaCS process after the CS in the nano HA + Ti systems are shown. First of all, it is necessary to remark on the more porous structure of the HA + Ti coating after the CS process only. Actually, adhesion degree for HA was significantly bad by our visual estimation in comparison with the CCDS process only. Obviously, the transfer from submicron to nano-sized particles of the HA has also added problems connected with nano-sized particle's agglomeration [14]. However, optimization of the laser regimes for the post process of the nano HA + Ti CS coatings was successful. More porous coating structure solidified and consolidated better after the laser treatment in comparison with the CCDS coatings and had no cracks nucleation. More flat solidified surface in the LaCS regime (Figure 5b) we considered as a desirable one. 


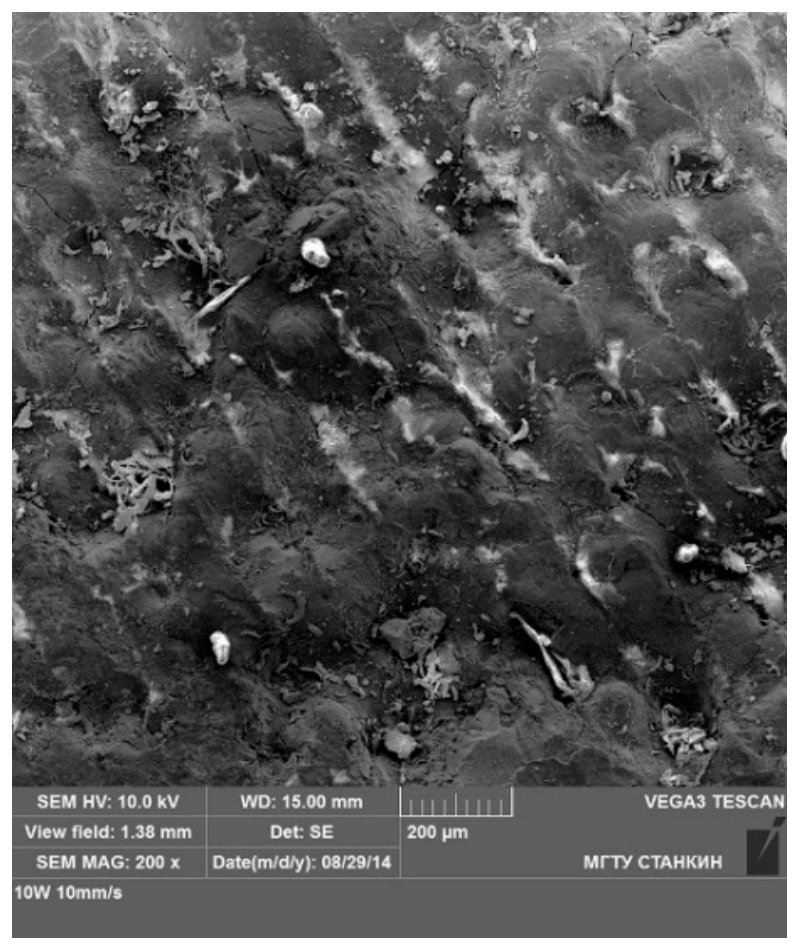

(a)

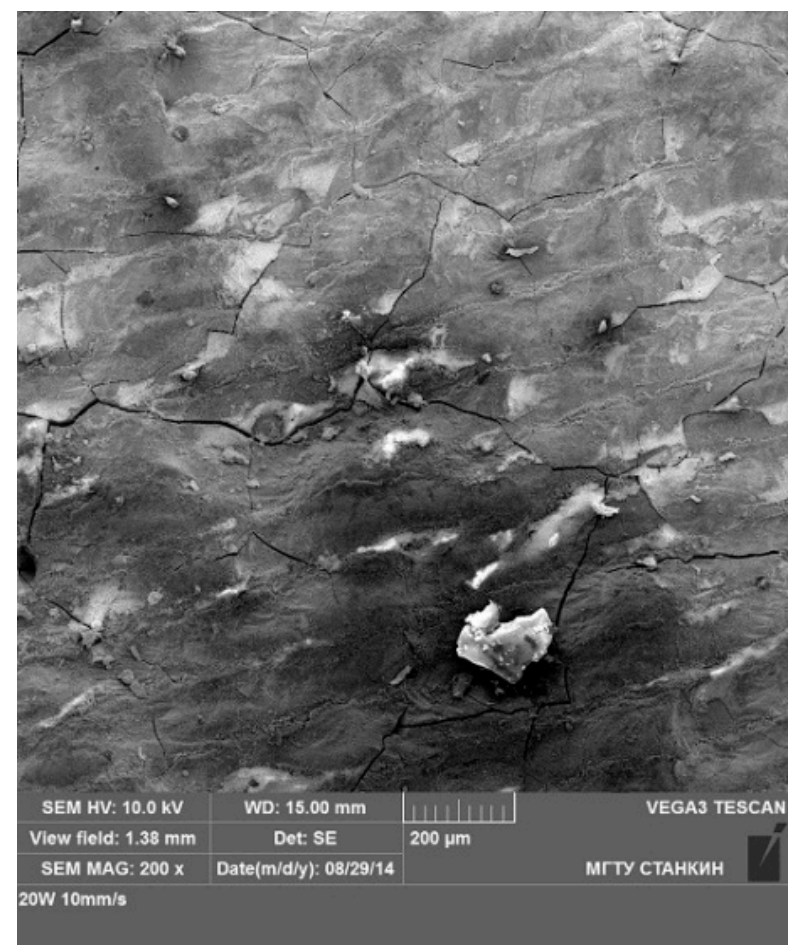

(b)

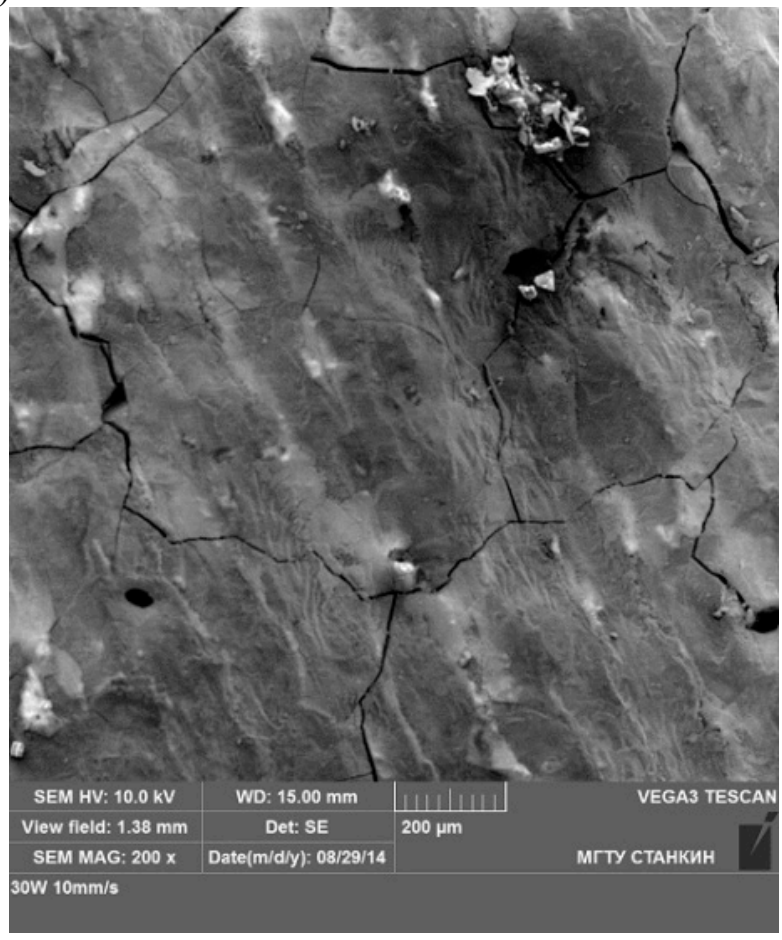

(c)

Figure 3. SEM image of laser treatment surface after the CCDS with the scan velocity $10 \mathrm{~mm} / \mathrm{s}$ : (a) $P=10 \mathrm{~W}$; (b) $P=20 \mathrm{~W}$; and (c) $P=30 \mathrm{~W}$. 


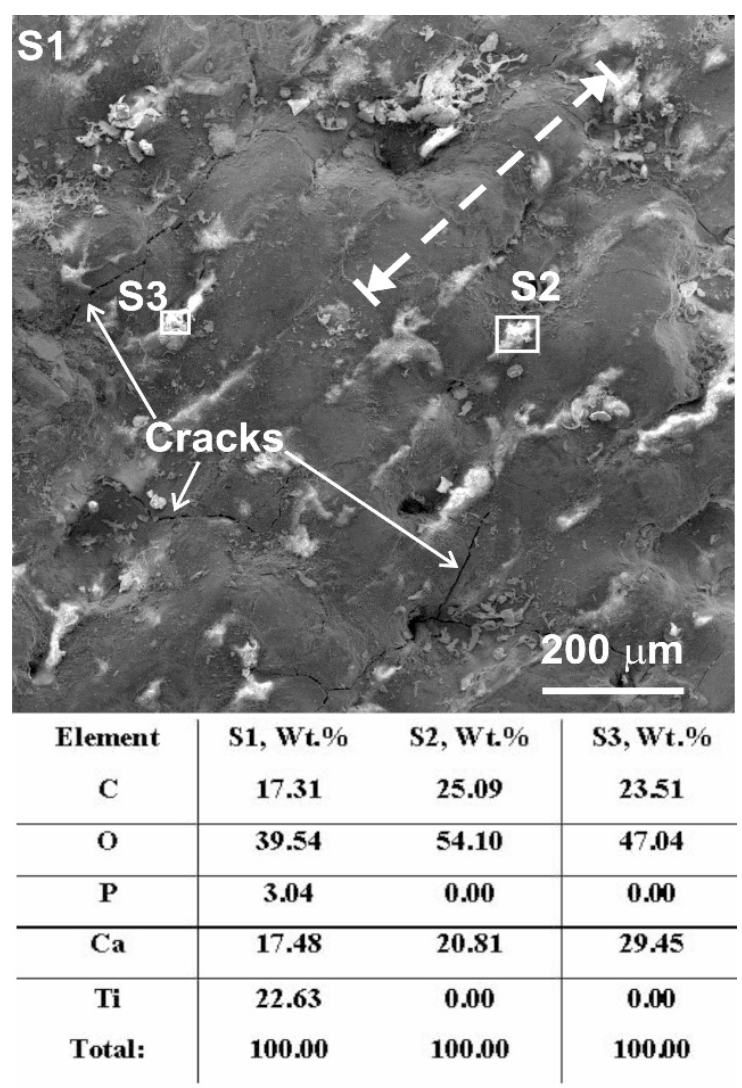

Figure 4. Peculiarities of the laser treated surface (Figure 3a) and EDX data by S1, S2 and S3 areas. Dotted line shows direction of the laser scanning.

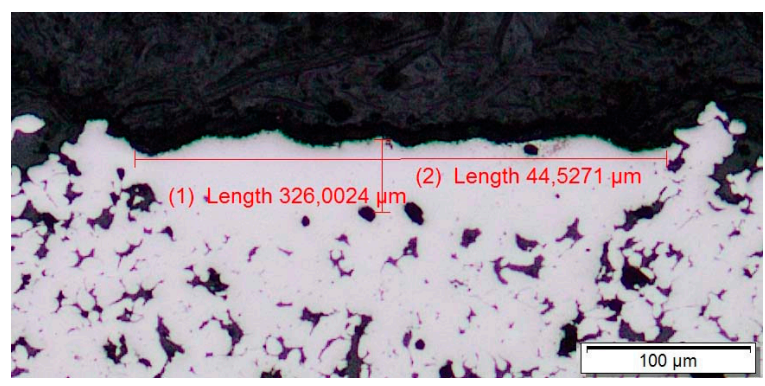

(a)

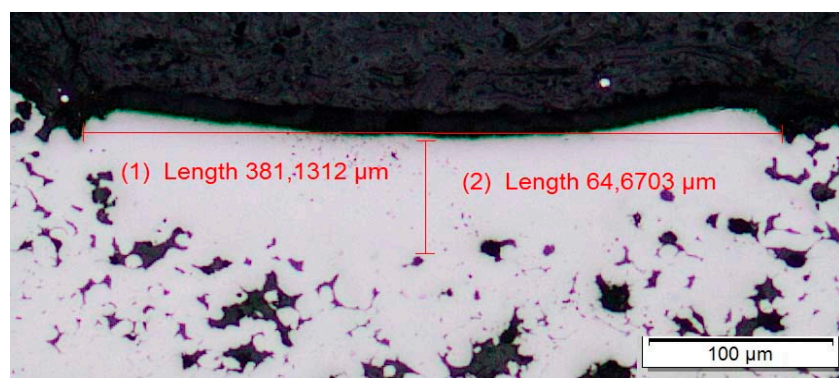

(b)

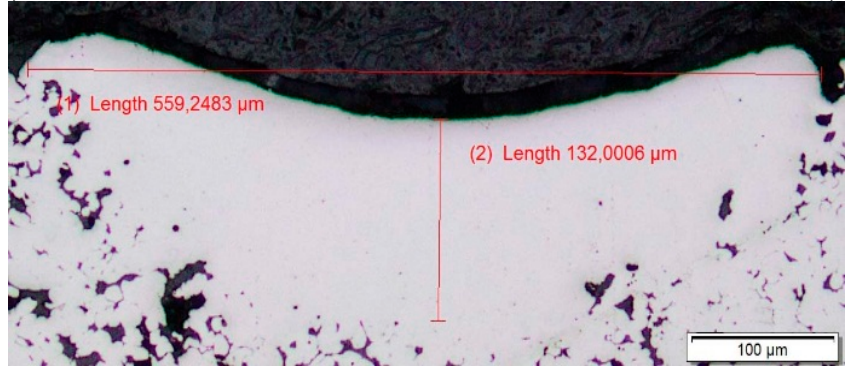

(c)

Figure 5. OM images of laser treatment surface after CS with scan velocity $10 \mathrm{~mm} / \mathrm{s}$ :

(a) $P=35 \mathrm{~W}$; (b) $P=55 \mathrm{~W}$; and (c) $P=90 \mathrm{~W}$.

Figure 6 shows the microstructure for this regime under high magnification. It is clearly seen that the homogenous remelting microstructure has cracks on the bottom of the laser affected zone remained 
(Figure 6b,d). The EDS microanalysis (Figure 6c) ensures the relatively homogenous Ca-Ti-P distribution by the whole volume. As an intermediate conclusion, we can recommend to control the depth of the CS coating. The decrease in coating thickness will provide a stronger connection and adhesion between the laser affected zone and the substrate $[12,14]$.

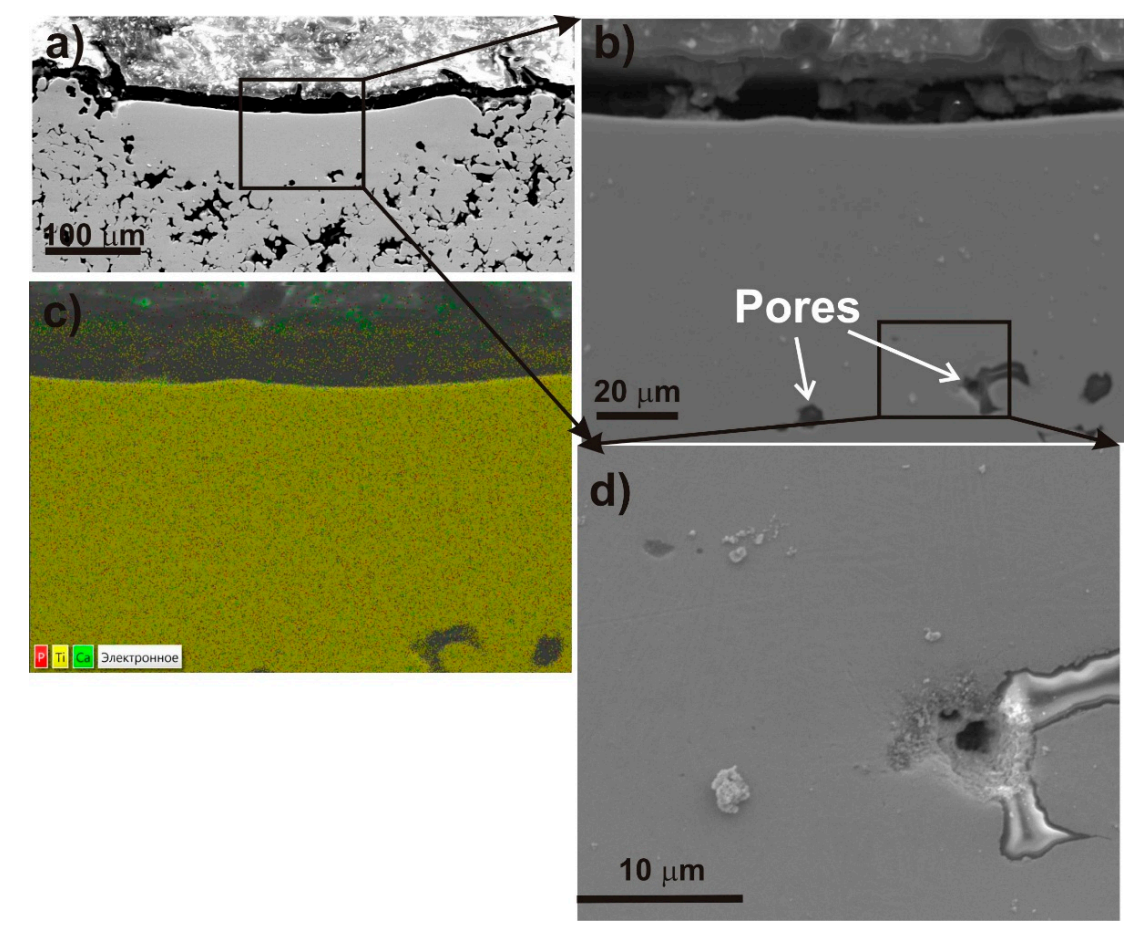

Figure 6. SEM of the CS coating after laser treatment: (a) regime of LI is presented in Figure 4b; (b,d) microstructure peculiarities under high magnification; and (c) the EDS microanalysis for whole area of Figure $6 b$.

It is known [18] that the maximum ceramic content in the metal-ceramic composites produced by CS is limited to about $20 \%-30 \%$, while the required ceramic content can be achieved using CCDS. In the first case, the non-deformed ceramic particles are more or less homogeneously distributed in the metal matrix, and in the second case, the ceramic compound is integrated into the metal matrix in the form of irregular thin layers. Thus, we can conclude that after the softened LaCS process the HA coating strength could be improved.

\subsection{Phase Analysis by XRD Patterns}

Comparative qualitative phase analysis after the LaCCDS and the LaCS processes are presented in Figure 7. We can observe the HA presence $\left(\mathrm{Ca}_{5}\left(\mathrm{PO}_{4}\right)_{3}(\mathrm{OH})\right.$, phase, JCPDS, card No. 24-0033) and $\alpha$-Calcium Phosphate $\left(\mathrm{CaP}_{4} \mathrm{O}_{11}\right.$ phase, JCPDS, card No. 49-0496) both after the LaCCDS and LaCS processes. Both have pharmacological features and are useful for future medical applications [16]. Earlier Kuznetsov et al. [17] informed that presence of HA in Ni-Ti mixture promoted formation of intermetallic phases $\mathrm{NiTi}_{2}$, NiTi and what mainly happened with $\mathrm{HA}$ was decomposition into $\mathrm{CaHPO}_{4}$ phase. Moreover, a $\mathrm{CaTiO}_{3}$ phase was found (JCPDS, card No. 82-0229), which indicates HA decomposition process as well as active oxidation of titanium during the laser treatment in the air ( $\mathrm{Ti}_{3} \mathrm{O}$ ) phase (JCPDS, card No. 72-1806). If the decomposition process is undesirable, so oxide films on 
the titanium surface are useful [1]. Comparing the phases after the LaCCDS and the LaCS processes shows that $\mathrm{CaTiO}_{3}$ phase presence is lower in the LaCS than after the LaCCDS process. Intensity lines after the LaCS were decreased in comparison with the LaCCDS, which we explain by nano structured grain size refinement.

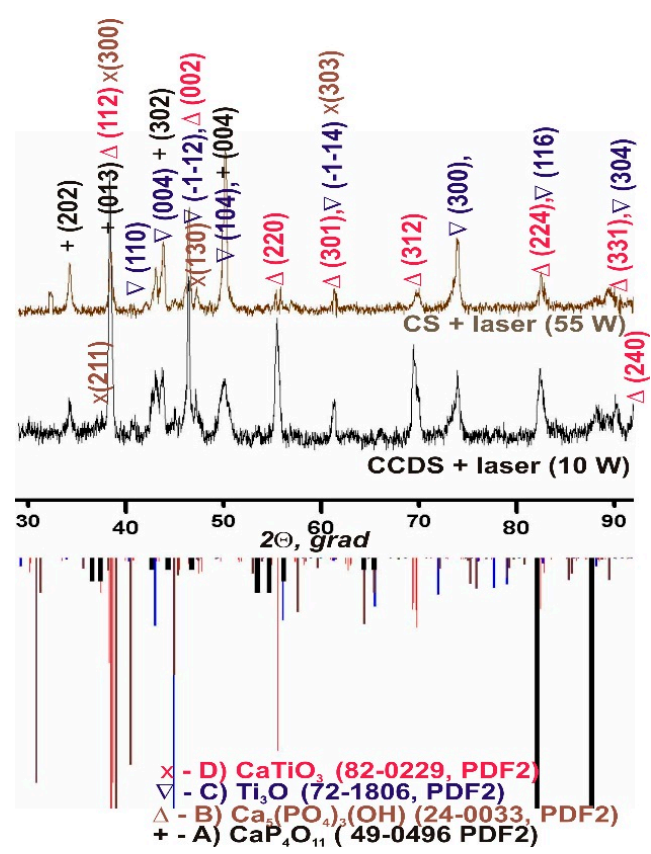

Figure 7. Comparative X-ray phase analysis of the CCDS and CS after laser treatment.

\section{Conclusions}

Laser annealed CCDS and CS processes were successfully realized in sub-micron HA + Ti systems for future medical applications. No significant modification of the initial HA composition was observed during the different steps of the coating preparation and spraying.

The laser treatment in a regime of softened annealing can be recommended for increasing the adhesion between HA and titanium coatings, because a high laser energy input leads to crack net development and HA decomposition in the case of the LaCCDS process.

The LaCS process can be recommended for HA + Ti coating fabrication under control of the CS coating thickness. In this case, these measures provide a stronger connection and adhesion between laser affected zone and substrate.

The SEM with energy dispersive X-ray analysis and comparative XRD phase analysis showed the LaCS process to be more attractive than the LaCCDS process by reasons of higher strength, ductility and absence of low HA destruction in the coatings.

\section{Acknowledgments}

The authors are deeply grateful to I. Smurov (Director of DIPI lab at ENISE, France and Director of LIAT at Stankin R.F.) for the organizational support and D. Pervushin (DIPI, ENISE) for experiments on the CCDS. The study was supported by the Russian Science Foundation (grant No. 14-19-00992). 


\section{Author Contributions}

Igor Shishkovsky conceived and designed the experiments; Victor Saphronov with $\mathrm{PhD}$ D. Pervushin performed the experiments and analyzed the data; Victor Saphronov conducted the optical metallography and the SEM with EDX microelement analysis; Igor Shishkovsky analyzed the XRD patterns and wrote the paper. All authors have read and approved the final manuscript.

\section{Conflicts of Interest}

The authors declare no conflict of interest.

\section{References}

1. Shishkovskii, I.; Morozov, Y.; Fokeev, S.; Volova, L. Laser synthesis and comparative testing of a three-dimensional porous matrix of titanium and titanium nickelide as a repository for stem cells. Powder Metall. Met. Ceram. 2012, 50, 606-618.

2. Citeau, A.; Guicheux, J.; Vinatier, C.; Layrolle, P.; Nguyen, T.; Pilet, P.; Daculsi, G. In vitro biological effects of titanium rough surface obtained by calcium phosphate grid blasting. Biomaterials 2005, 26, 157-165.

3. Sygnatowicz, M.; Tiwari, A. Controlled synthesis of hydroxyapatite-based coatings for biomedical application. Mater. Sci. Eng. C 2009, 29, 1071-1076.

4. Lee, K.W.; Wang, S.; Yaszemski, M.J.; Lu, L. Physical properties and cellular responses to crosslinkable poly(propylene fumarate)/hydroxyapatite nanocomposites. Biomaterials 2008, 29, 2839-2848.

5. Wang, S.; Kempen, D.H.R.; Yaszemski, M.J.; Lu, L. The roles of matrix polymer crystallinity and hydroxyapatite nanoparticles in modulating material properties of photo-crosslinked composites and bone marrow stromal cell responses. Biomaterials 2009, 30, 3359-3370.

6. Cai, L.; Guinn, A.S.; Wang, S. Exposed hydroxyapatite particles on the surface of photo-crosslinked nanocomposites for promoting MC3T3 cell proliferation and differentiation. Acta Biomater. 2011, 7, 2185-2199.

7. Shishkovsky, I.; Scherbakov, V. Selective laser sintering of biopolymers with micro and nano ceramic additives for medicine. Phys. Procedia 2012, 39, 491-499.

8. Shishkovsky, I.; Volchkov, S. Influence of the laser assisted fabricated 3D porous scaffolds from bioceramoplasts of micron and nano sizes on culture of MMSC. Proc. SPIE 2013, 9065, doi:10.1117/12.2035550.

9. D’Haese, R.; Pawlowski, L.; Bigan, M.; Jaworski, R.; Martel, M. Phase evolution of hydroxapatite coatings suspension plasma sprayed using variable parameters in simulated body fluid. Surf. Coat. Technol. 2010, 204, 1236-1246.

10. Arias, J.; Mayor, M.; Garcia-Sanz, F.; Pou, J.; Loen, B.; Perez-Amor, M.; Knowles, J. Structural analysis of calcium phosphate coatings produced by pulsed laser deposition at different water-vapour pressures. J. Mater. Sci. Mater. Med. 1997, 8, 873-876. 
11. Pattison, J.; Celotto, S.; Morgan, R.; Bray, M.; O’Neill, W. Cold gas dynamic manufacturing: A non-thermal approach to freeform fabrication. Intern. Mach. Tools Manuf. 2007, 47, 627-634.

12. Kalita, V.; Gnedovets, A. Porous coatings: Experiments, modeling, and biomedical applications. Plasma Process. Polym. 2005, 2, 485-492.

13. Shtansky, D.; Batenina, I.; Yadroitsev, I.; Ryashin, N.; Kiryukhantsev-Korneev, P.H.; Kudryashov, A.; Sheveyko, A.; Zhitnyak, I.; Gloushankova, N.; Smurov, I.; et al. A new combined approach to metal-ceramic implants with controllable surface topography, chemistry, blind porosity, and wettability. Surf. Coat. Technol. 2012, 208, 14-23.

14. Shishkovsky, I. Chemical and physical vapor deposition methods for nanocoatings. In Nanocoatings and Ultra Thin-Films: Technologies and Applications; Hamdy, A.S., Tiginyanu, I., Eds.; Woodhead Publishing Limited: Cambridge, UK, 2011; pp. 57-77.

15. Lynn, A.; DuQuesnay, D. Hydroxyapatite-coated Ti-6Al-4V Part 1: The effect of coating thickness on mechanical fatigue behaviour. Biomaterials 2002, 23, 1937-1946.

16. Shishkovsky, I.; Tarasova, E.; Zhuravel', L.; Petrov, A. The synthesis of a biocomposite based on nickel titanium and hydroxyapatite under selective laser sintering conditions. Tech. Phys. Lett. 2001, 27, 211-213.

17. Kuznetsov, M.; Morozov, Y.; Parkin, I.; Shishkovsky, I. Design of 3D functional articles by combined SHS-SLS. Mater. Manuf. Process. 2008, 23, 571-578.

18. Sova, A.; Pervushin, D.; Smurov, I. Development of multimaterial coatings by cold spray and gas detonation spraying. Surf. Coat. Technol. 2010, 205, 1108-1114.

19. Sova, A.; Papyrin, A.; Smurov, I. Influence of ceramic powder size on process of cermet coating formation by cold spray. J. Therm. Spray Technol. 2011, 20, 285-291.

20. Pervushin, D.; Shishkovsky, I.; Smurov, I. Gas-dynamic spraying of hydroxyapatite on medical instruments from titanium alloy. Russ. J. Non-Ferrous Met. 2014, 55, 298-302.

21. Bray, M.; Cockburn, A.; O’Neill, W. The Laser-assisted Cold Spray process and deposit characterization. Surf. Coat. Technol. 2009, 203, 2851-2857.

22. Zhang, M.; Cheng, G. Nanoscale size dependence on pulsed laser sintering of hydroxyapatite/titanium particles on metal implants. J. Appl. Phys. 2010, 108, doi:10.1063/1.3504612.

23. Suutala, J.; Tuominen, J.; Vuoristo, P. Laser-assisted spraying and laser treatment of thermally sprayed coatings. Surf. Coat. Technol. 2006, 201, 1981-1987.

24. Christoulis, D.; Jeandin, M.; Irissou, E.; Legoux, J.; Knapp. W. Laser-Assisted Cold Spray (LACS). In Nd YAG Laser; InTech: Rijeka, Croatia, 2012. Available online: http://www.intechopen.com/ books/nd-yag-laser/laser-assisted-cold-spray-lacs- (accessed on 30 September 2015).

25. Podrabinnik, P.; Grigoriev, S.; Shishkovsky, I. Laser post annealing of cold-sprayed Al/alumina-Ni composite coatings. Surf. Coat. Technol. 2015, 271, 265-268.

(C) 2015 by the authors; licensee MDPI, Basel, Switzerland. This article is an open access article distributed under the terms and conditions of the Creative Commons Attribution license (http://creativecommons.org/licenses/by/4.0/). 